\title{
EFFECT OF ISCHAEMIA ON MEMBRANE-BOUND HYDROLASES IN RAT SOLEUS CAPILLARIES
}

\author{
K. N. CHRISTIE AND G. THOMSON \\ Department of Anatomy, The University, Dundee DD1 4HN, Scotland, UK
}

Received for publication November 8, 1988 and in revised form January 17, 1989

\begin{abstract}
Ischaemia in rat soleus muscles induced with a single high dose of 5-hydroxytryptamine caused a loss of activity of alkaline phosphatase, aminopeptidase $\mathbf{A}$ and dipeptidyl peptidase IV from capillaries adjacent to and within the most severe muscle lesions. Three days after the insult about $75 \%$ activity had returned to the capillaries, and by 6 days normal levels were restored. Loss and recovery of enzyme activity was paralleled by degeneration and regeneration of the muscle fibres.
\end{abstract}

Muscle degenerates and dies when its vascular system is impaired. This can be dramatically demonstrated in rats given a single high dose of 5-hydroxytryptamine (5HT) $(1,5,10-12)$. In this model of ischaemia, red aerobic muscles such as the soleus are selectively damaged, while anaerobic muscles like extensor digitorum longus are largely spared. About three days after 5-HT administration the muscles begin to show signs of recovery and are usually back to normal five weeks later. While this model has proved excellent for studying enzymic changes during degeneration and regeneration in muscle, little attention has been paid to its value for the study of similar changes in the microvasculature. As part of our continuing investigations into the role of hydrolytic and proteolytic enzymes in normal and myopathic muscles, we decided to examine the activities of three membrane-bound enzymes of this class, alkaline phosphatase (EC 3.1.3.1), aminopeptidase A (APA) (EC 3.4.11.7) and dipeptidyl peptidase IV (DPP IV) (EC 3.4.14.5) in soleus capillaries using quantitative cytochemical techniques during the onset and recovery phases of a 5-HT ischaemic insult. The questions which we hoped to answer were (1) are there alterations to the activities of any or all of these enzymes during the induction of the myopathy, and (2) is there any relationship between the levels of activity in the capillaries and muscle regeneration during the first few days of recovery?

\section{MATERIALS AND METHODS}

\section{Animals and 5-HT administration}

Fourteen male, 3-month old Wistar rats weighing approximately $250 \mathrm{~g}$ were each injected with the equivalent of $10 \mathrm{mg}$ 5-hydroxytryptamine $(5-\mathrm{HT})$ per $\mathrm{kg}$ body weight. The creatine sulphate complex was obtained from the Sigma Chemical Co. Ltd (Poole, England) and dissolved in $0.9 \% \mathrm{w} / \mathrm{v} \mathrm{NaCl}$. A further two rats were injected with saline alone to serve as controls. All rats were allowed free access to food 
and water for the duration of the experiment. Two rats were killed by stunning and cervical dislocation at the following time intervals after 5-HT administration: $30 \mathrm{~min}$, $1 \mathrm{hr}, 2 \mathrm{hr}, 4 \mathrm{hr}, 24 \mathrm{hr}, 72 \mathrm{hr}$ and $144 \mathrm{hr}$.

Cryotomy and histology

Both soleus muscles were removed from each animal and mid-belly portions supported in $10 \% \mathrm{w} / \mathrm{v}$ gum tragacanth on cork discs quenched in liquid nitrogen. $10 \mu \mathrm{m}$-thick, fresh, transverse and longitudinal sections were cut in a motorised cryostat run at constant speed and mounted on coverslips. After fixation in Clarke's fluid (4), some sections were stained with Haematoxylin and Eosin, others, unfixed, were stained by the NADH-tetrazolium reductase method (7). Both techniques were used to assess the extent of ischaemic damage in the muscles.

Enzyme histochemistry

Alkaline phosphatase activity was detected against 5-brom-4-chloro-3-indolyl phosphate at $\mathrm{pH} 9.4$ using tetranitro $\mathrm{BT}$ as the tetrazolium salt (7). Fresh cryostat sections were incubated for $30 \mathrm{~min}$ at $37^{\circ} \mathrm{C}$, rinsed in distilled water, fixed in $4 \%$ formaldehyde and mounted in glycerine jelly. Controls consisted of incubation in the absence of the substrate or preincubation and incubation in the presence of $1 \mathrm{mM} \mathrm{L}$ tetramisol.

Aminopeptidase A activity was determined against L-glutamic acid-4-methoxy$\beta$-naphthylamide (Bachem, Switzerland). The method was that of Lojda and Gossrau (1980) using liquid media, except that tetrazotized dimethoxybenzidine fluoroborate (TDMBF) was substituted for Fast Blue BB and the concentration reduced to $0.5 \mathrm{mg} / \mathrm{ml}$. Fresh cryostat sections on coverslips were incubated for $1 \mathrm{hr}$ at $37^{\circ} \mathrm{C}$, rinsed in distilled water and mounted in glycerine jelly. The control procedure consisted of incubation in the presence of amastatin $(0.02 \mathrm{mM})$.

Dipeptidyl peptidase IV was detected by hydrolysis of glycyl-L-proline-4methoxy- $\beta$-naphthylamide (Bachem, Switzerland) at a final substrate concentration of $1 \mathrm{mg} / 2.5 \mathrm{ml}$ in $0.1 \mathrm{mM}$ cacodylate buffer, $\mathrm{pH} 7.4$. TDMBF was again substituted for Fast Blue BB but this time at a final concentration of $1 \mathrm{mg} / 2.5 \mathrm{ml}$. Fresh sections on coverslips were incubated for $1 \mathrm{~h}$ at $37^{\circ} \mathrm{C}$, rinsed in distilled water, fixed in $4 \%$ formaldehye and mounted in glycerine jelly. Confirmation of identity was obtained using diprotin A $(0.3 \mathrm{mM})$ in the substrate medium, a potent DPPIV inhibitor.

Microdensitometry of enzyme reaction product

Scanning microdensitometry was carried out with a Vickers M85 microdensitometer. The machine settings were as follows: objective $\times 40$, spot size $1,530 \mathrm{~nm}$ (APA and DPPIV) and $550 \mathrm{~nm}$ (Alk. phos.). The latter are the reaction product absorption maxima. Twenty four capillary profiles were measured in the most severely damaged regions in transverse sections of soleus. Preliminary experiments indicated that this number was sufficient to give a constant cumulative mean absorbance and standard deviation.

\section{RESULTS}

\section{Histology}

No sign of damage to the muscles was evident 30 min after 5 - $\mathrm{HT}$ administration. After $1 \mathrm{~h}$ many fibres showed vacuolation, rounding, loss of eosinophilia and interstitital oedema (Fig. 1). These early changes were amplified in NADH prepara- 
tions which showed marked clumping and densification of mitochondrial reaction product in some fibres and loss of product in others (Figs. 2, 3). $4 \mathrm{hr}$ after administration there was an increase in the number of affected fibres, oedema had increased and macrophages and leukocytes were abundant in the inflammatory exudate and within degenerating fibres. The picture at $24 \mathrm{~h}$ was similar except that necrotic fibres now predominated in various stages of phagocytosis and dissolution. 3 days after 5-HT most of the muscle fibres had been removed and clusters of myoblasts were evident as were recovered or regenerated capillaries. At 6 days most of the myoblasts had aggregated into putative myotubes and immature, central-nucleated fibres could now be resolved (Fig. 4).
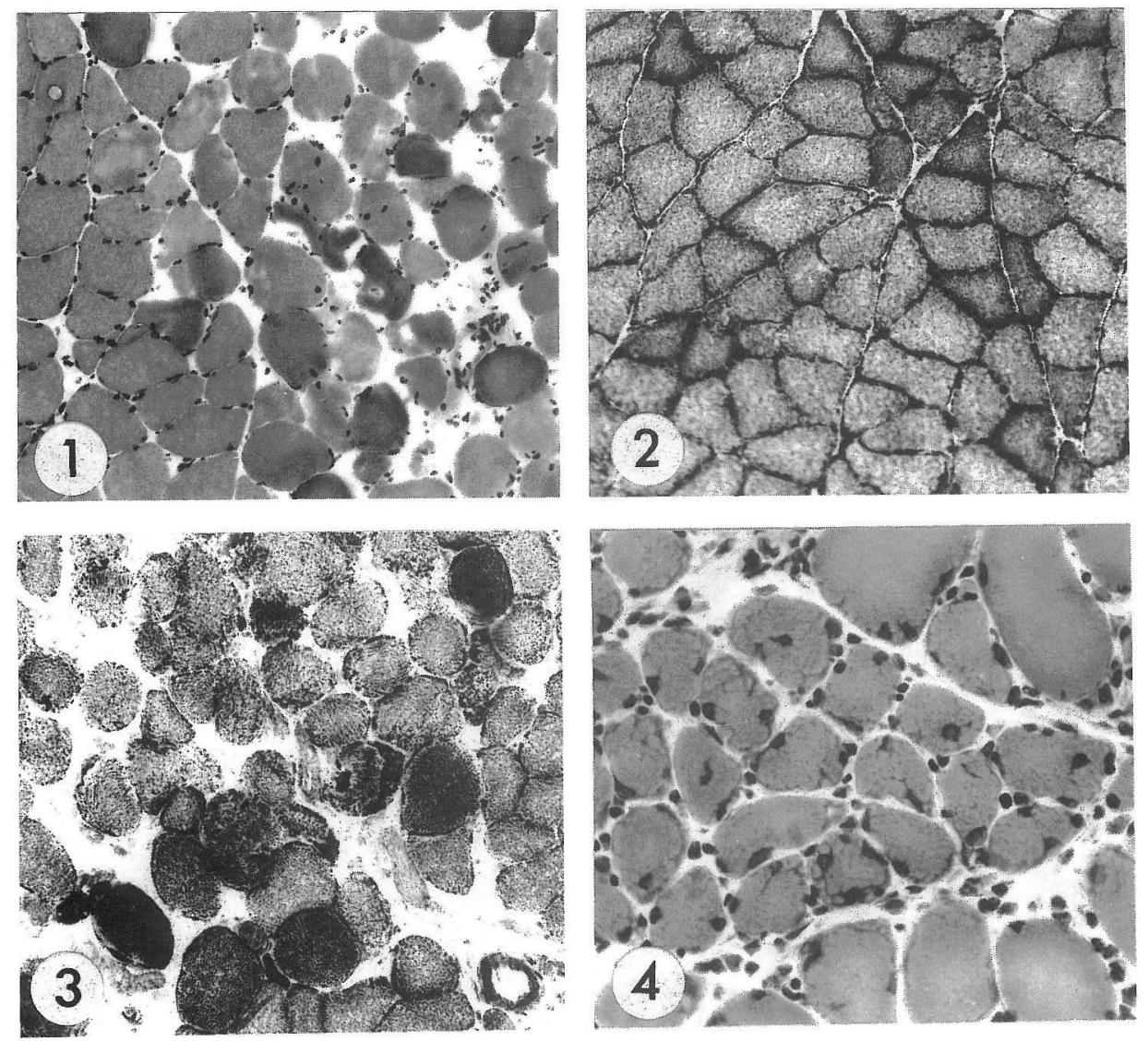

FIG. 1. Rat soleus $1 \mathrm{hr}$ after 5-HT administration. Rounding, loss of eosinophilia and vacuolation of fibres is already evident. H\&E. $\times 125$

FIG. 2. Control rat soleus stained for NADH-tetrazolium reductase. $\times 125$

FIG. 3. Rat soleus $1 \mathrm{hr}$ after 5-HT administration. Clumping, fragmentation and loss of mitochondrial reaction product is a prominent feature even at this early stage. NADH-tetrazolium reductase. $\times 125$

FIG. 4. Rat soleus 6 days after 5-HT administration. Immature, central-nucleated fibres now occupy the formerly damaged areas. H\&E. $\quad \times 210$ 


\section{Capillary alkaline phosphatase}

Capillaries in control soleus muscles exhibited a strong reaction product (Fig. 5). Following 5-HT treatment, activity decreased dramatically up to $24 \mathrm{~h}$ when no activity was detectable in capillaries associated with the most severely damaged fibres (Fig. 6). Three days post-5-HT, alkaline phosphatase activity returned to capillaries adjacent to myoblasts regaining $83 \%$ of the absorbance of control samples. By 6 days, mean absorbance in areas of regenerating muscle exceeded control levels by about 16\% (Figs. 7, 8).

Capillary aminopeptidase $A$

In control animals, a smaller proportion of the capillary network exhibited aminopeptidase A activity compared to alkaline phosphatase (Fig. 9). During the first $4 \mathrm{hr}$ after 5-HT adminsitration, activity in capillaries in areas of damaged muscle decreased by about $50 \%$ (Fig. 10). After $24 \mathrm{~h}$ no activity remained in vessels in areas of greatest muscle damage. Three days after insult, $64 \%$ activity returned to capillaries associated with clusters of myoblasts, and by 6 days normal levels were fully restored (Figs. 11, 12).

Capillary dipeptidyl peptidase IV

The proportion of the capillary network exhibiting DPPIV activity in normal soleus was somewhat greater than aminopeptidase A but less than alkaline phosphatase (Fig. 13). " $4 \mathrm{~h}$ after 5-HT, activity in the worst affected aveas dropped by about $40 \%$ ". $24 \mathrm{~h}$ later, even in the most severely damaged areas, the proportion of DPPIV-reactive capillaries remained roughly the same, as did the activity, about $40 \%$ (Fig. 14). Three days after the administration of $5-\mathrm{HT}, 78 \%$ activity was restored to vessels adjacent to myoblasts, and by 6 days this had increased to approximately $107 \%$ (Figs. 15, 16).

FIG. 5. Control rat soleus showing typical capillary localisation of alkaline phosphatase. $\quad \times 125$

FIg. 6. Rat soleus 24 hours after 5-HT. Oedema and damaged fibres with absent or fragmented capillaries are evident. Alkaline phosphatase. $\times 125$

FIG. 7. Rat soleus 6 days after 5-HT. Capillaries adjacent to regenerating fibres display strong alkaline phosphatase activity. $\quad \times 210$

Fig. 8. Alkaline phosphatase reaction product absorbances in capillaries as a function of time after 5-HT administration (Means \pm S.D.).

Fig. 9. Control rat soleus reacted for APA. Note the less extensive distribution and reduced amount of reaction product generally. $\times 210$

FIG. 10. Rat soleus 4 hours after 5-HT. APA is considerably reduced in activity. $\quad \times 210$

Fig. 11. Rat soleus 6 days after 5-HT. Longitudinal section showing strong APA activity in vessels alongside regenerating fibres. $\times 210$

Fig. 12. Aminopeptidase A reaction product absorbances in capillaries as a function of time after 5HT administration (Means \pm S.D.).

FIg. 13. Control rat soleus reacted for DPPIV. Like APA the reaction product is less extensive than alkaline phosphatase. $\quad \times 210$

FIG. 14. Rat soleus 24 hours after 5-HT. About 40\% DPPIV activity remained in vessels in preparations such as this where the fibres are clearly damaged. DPPIV. $\quad \times 210$

FIG. 15. Rat soleus 6 days after 5-HT. Capillaries associated with regenerating fibres display strong DPPIV activity. $\quad \times 210$

FIG. 16. Dipeptidyl peptidase IV reaction product absorbances in capillaries as a function of time after 5-HT (Means \pm S.D.). 

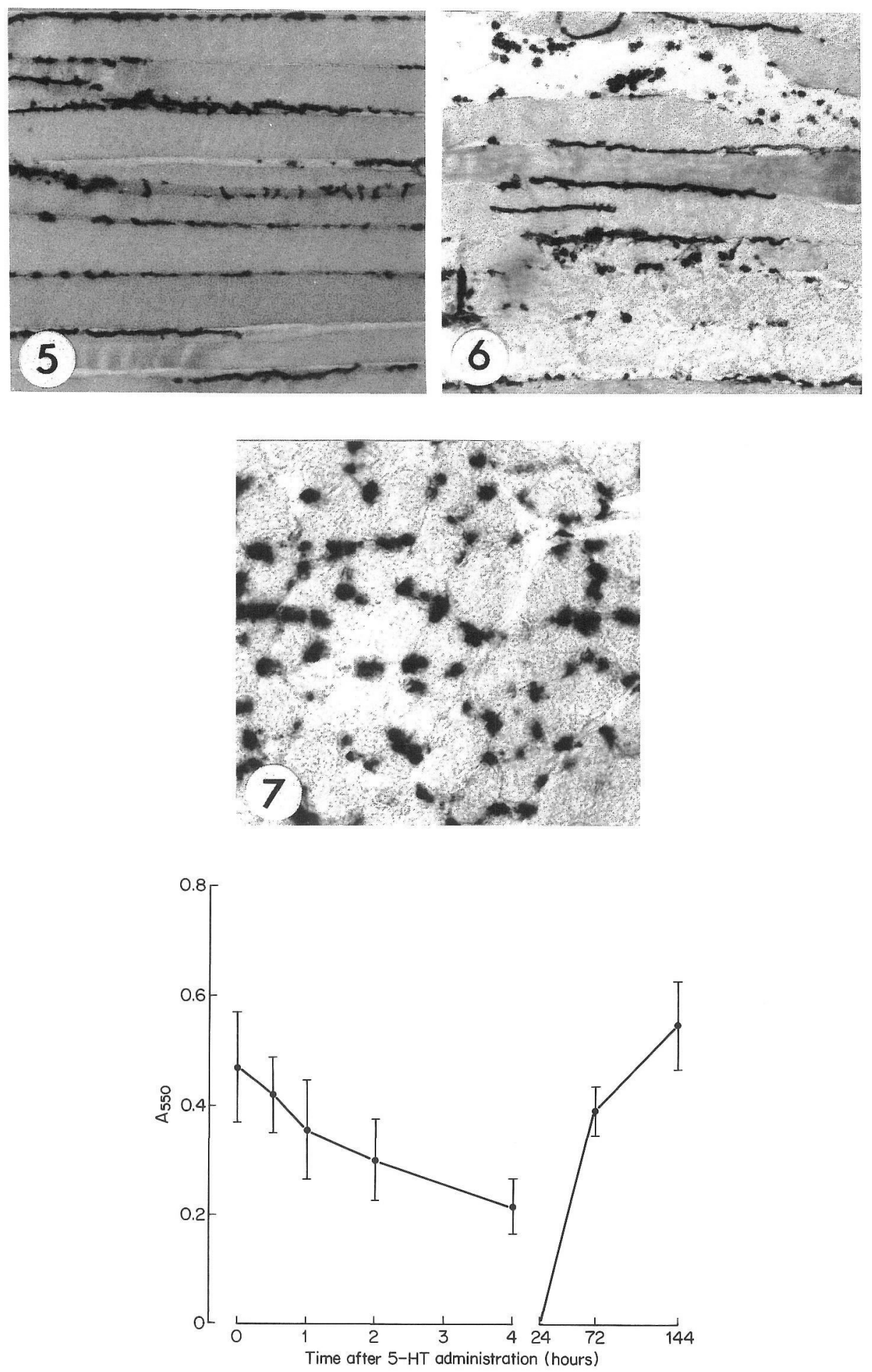

FIG. 8. 

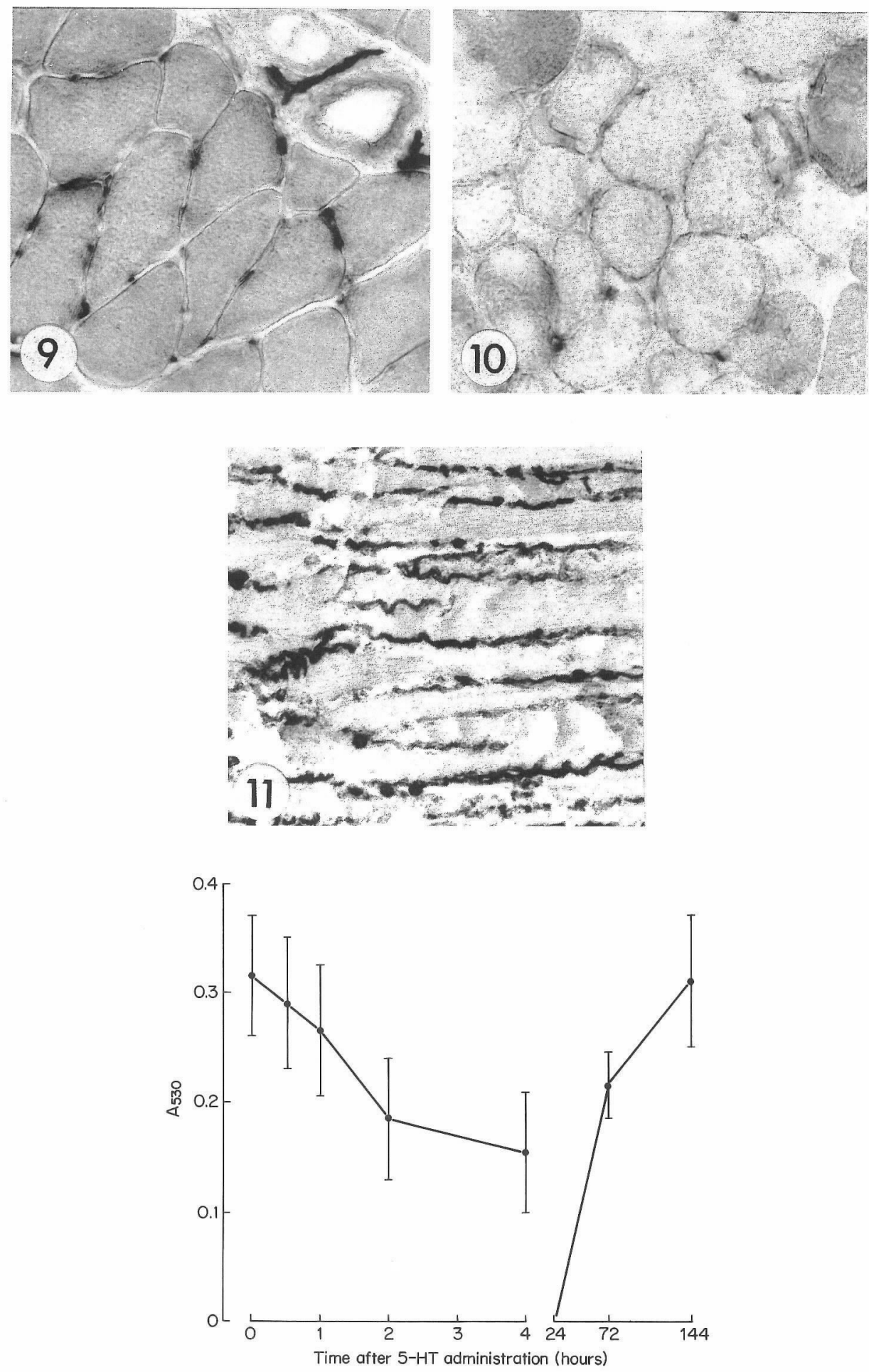

FIG. 12. 

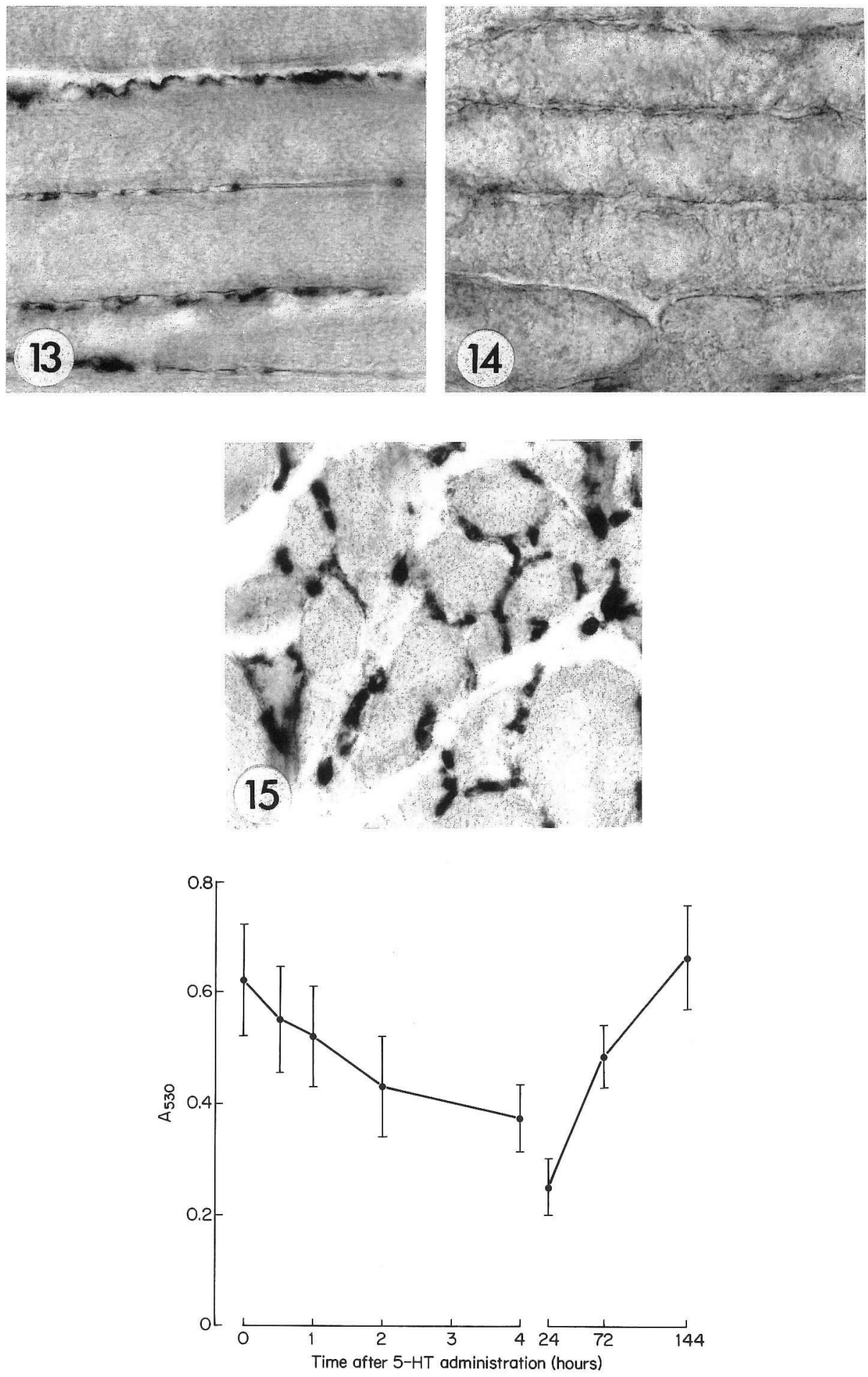

FIG. 16. 


\section{DISCUSSION}

Ischemia in muscle induced with 5-HT provides a good model for studying both capillary enzyme activities and associated muscle fibre perturbation. In this study a close relationship was evident between the two. Changes in capillary enzyme activity were reflected by morphological and enzymic alterations in the muscle fibres during onset and recovery from the insult. All three enzymes were reduced in activity to about the same extent during the first $4 \mathrm{~h}$ of ischaemia. $24 \mathrm{~h}$ later, alkaline phosphatase and aminopeptidase A were completely absent from capillaries in the most severely damaged regions of soleus, while DPP IV retained about $40 \%$ of its original activity in equivalent areas (Figs. 8, 12, 16). Three days after 5-HT the activities of all three enzymes had recovered to about $75 \%$ of their original activities in capillaries adjacent to myoblasts, and by 6 days they were effectively back to normal in sites close to myotubes and immature fibres.

The role of all three enzymes in the vascular system is unknown. Alkaline phosphatase, a $\mathrm{Zn}$ metalloenzyme, is a nonspecific phosphomonoesterase which participates in the transfer of phosphate from one phosphate ester linkage to another (2), which in muscle, is chiefly located in the endothelium of arterioles and the arterial portion of capillaries (6). DPPIV is a serine peptidase which removes $\mathrm{N}$-terminal dipeptides sequentially from polypeptides with unsubstituted $\mathrm{N}$-termini (9) and is confined to endothelial cells of the venous part of the capillary network (6). By virtue of its action on the glycyl-proline sequence it has been suggested that DPPIV may mediate in the synthesis of the endothelial cell collagen coat (6). Aminopeptidase A is also confined to the venous portion of the capillary bed in skeletal muscles (8). Unlike the other two hydrolases, however, the presence of APA in capillaries seems more appropriate. Pharmacological experiments show that APA functions as an 'angiotensinase'. By its removal of the terminal Asp from the octapeptide angiotensin II, APA can reduce pressor activity by as much as $75 \%$ (3).

We have shown that the loss of activity of all three membrane-bound hydrolases in capillaries is directly related to endothelial cell injury or death, while restoration probably indicates recovery or regeneration. These features are mirrored in the muscle where destruction and reinstatement of the vascular system coincides with fibre degeneration and regeneration.

\section{REFERENCES}

1. Christie, K. N. and Thomson, C.: Relative activities of acid phosphatase and dipeptidyl peptidase II in regenerating rat skeletal muscle fibres. Acta histochem. cytochem. 20; 527-535, 1987.

2. Coleman, J. E. and Gettings, P.: Alkaline phosphatase, solution structure, and mechanism. In Ad. Enzymology, vol. 55, ed. by A. Meister, J. Wiley \& Sons, New York, 1983, pp. 381-452.

3. Douglas, W. W.: Polypeptides-angiotensin, plasma kinins, and other vasoactive agents; prostaglandins. In The Pharmacological Basis of Therapeutics, ed. by L. S. Goodman, A. Gilman, A. G. Gilman and G. B. Koelle, McMillan Pub. Co., New York, 1975, pp. 630-652.

4. Hopwood, D.: Fixation and fixatives. In Theory and Practice of Histological Techniques, ed. by J. D. Bancroft and A., Stevens, Churchill Livingstone, Edinburgh, 1977, pp. 16-28.

5. Kelts, K. A. and Kaiser, K. K.: Experimental ischaemic myopathy. J. Neurol. Sci. 40; 23-27, 1979. 
6. Lojda, Z.: Studies on dipeptidyl (amino) peptidase IV (glycyl-proline naphthylamidase). II Blood vessels. Histochemistry 59; 153-166, 1979.

7. Lojda, Z., Gossrau, R. and Schiebler, T. H.: Enzyme Histochemistry, Springer Verlag, Berlin, 1977.

8. Lojda, Z. and Gossrau, R.: Study on aminopeptidase A. Histochemistry 67; 267-290, 1980.

9. McDonald, J. K. and Barratt, A. J.: Mammalian Proteases, vol. 2., Exopeptidases, Academic Press, London, 1986, pp. 132-144.

10. Munsat, T. L., Hudgson, P. and Johnson, M. A.: Experimental serotonin myopathy. Neurol. (Minneap.) 27; 772-782, 1977.

11. O'Steen, W. K., Barnard, J. L. and Yates, R. D.: Morphological changes in skeletal muscle induced by serotonin treatment: a light and electron microscopic study. Exptl. Mol. Path. 7; 145-155, 1967.

12. Stoward, P. J., Christie, K. N. and Thomson, C.: Dipeptidyl peptidases in the soleus muscle of the rat before and after treatment with 5-hydroxytryptamine. Histochemistry 89; 11-24, 1988. 